\title{
AS TRANSFORMAÇÕES DO CERRADO EM MORRINHOS (GO): UMA HISTÓRIA NARRADA PELO ASSENTAMENTO TIJUQUEIRO
}

THE TRANSFORMATIONS OF CERRADO IN MORRINHOS (GO): A STORY NARRATED BY THE TIJUQUEIRO SETTLEMENT

\section{Ressiliane Ribeiro Prata-Alonso}

Doutora em Ciências Biológicas (Botânica) pelo Instituto Nacional de Pesquisas da Amazônia (INPA). Professora e Coordenadora do Curso de Graduação em Engenharia Agronômica da Faculdade Araguaia. Vice-Coordenadora do Núcleo de Estudos e Pesquisas sobre Educação Rural no Brasil (NEPERBR/UEG) Morrinhos (GO), Brasil.

\section{Flávio Reis dos Santos}

Doutor em Educação pela Universidade Federal de São Carlos (UFSCar). Professor do Programa de Pós-Graduação em Ambiente e Sociedade da Universidade Estadual de Goiás (UEG). Pesquisador do Grupo de Estudos e Pesquisas sobre Educação do Campo (GEPEC/HISTEBR/UFSCar). Coordenador do NEPERBR/UEG Morrinhos (GO), Brasil.

\section{Endereço para correspondência:} Ressiliane Ribeiro Prata-Alonso Avenida T-10, 1047, Setor Bueno74223-060 - Goiânia (GO), Brasil E-mail: ressiliane@yahoo.com.br

Recebido: $15 / 06 / 2016$

Aceito: 06/07/2017

\section{RESUMO}

Os objetivos deste trabalho foram identificar o perfil do produtor rural do Assentamento Tijuqueiro (AT) e caracterizar suas concepções sobre o que o Cerrado "era" e as transformações ocorridas de flora e fauna até os dias atuais em Morrinhos, Goiás. Entrevistas não diretivas com moradores do referido assentamento, a partir da delimitação da amostra intencional não probabilística realizadas com dez famílias, mostraram que as atividades agropecuárias empreendidas há décadas em Morrinhos contribuem para a diminuição da biodiversidade, com relatos de espécies de plantas e animais não mais visualizadas em decorrência do desmatamento do Cerrado local. Os moradores do AT expressam grande preocupação com a preservação do pouco que restou da vegetação original em Morrinhos e reiteram que é preciso empreender ações imediatas para reverter a deplorável situação desse bioma na região e evitar a expansão da destruição da biodiversidade com a destinação de áreas de reserva florestal em suas propriedades.

Palavras-chave: produtor rural; conservação; agronegócio; ambiente.

\section{ABSTRACT}

The objectives of this study were to identify the profile of the rural producers of the Tijuqueiro Settlement (TS) and to characterize their conceptions of what the Cerrado "was" and the changes of flora and fauna to the present day in Morrinhos, Goiás, Brazil. Non-directive interviews with residents of the settlement, from the delimitation of the non-probabilistic intentional sample carried out with ten families, showed that the agricultural activities undertaken for decades in Morrinhos contribute to the reduction of biodiversity, with reports of plants and animals species no longer visualized as a result of deforestation of the local Cerrado. The residents of the ST express great concern about the preservation of the little that remains of the original vegetation in Morrinhos and reiterate that immediate actions must be taken to reverse the deplorable situation of this biome in the region and to avoid the expansion of the destruction of biodiversity with the destination of areas of forest reserves on their properties.

Keywords: rural producers; conservation; agribusiness; environment. 


\section{INTRODUÇÃO}

O município de Morrinhos, localizado na região sul do estado de Goiás, destaca-se por impulsionar a economia da região ao concentrar a maior parte de suas atividades produtivas em áreas rurais. Possui uma população estimada de 44.607 habitantes, distribuída em uma área territorial de $2.846,199 \mathrm{~km}^{2}$, conforme informações do Instituto Brasileiro de Geografia e Estatística (IBGE, 2015). Mais da metade da produção do município (53\%) advém do setor agropecuário, no qual se verifica a predominância de associações no uso da terra, destaque para a cultura de soja, milho, arroz, feijão, tomate, mandioca etc. A pecuária apresenta um rebanho de bovinos em torno 250 mil cabeças, tanto destinadas ao corte (carne), quanto à produção leiteira, que ultrapassa a barreira de 60 milhões de litros por ano.

Morrinhos é um dos maiores responsáveis pelo abastecimento de produtos lácteos no estado de Goiás, por meio das atividades produtivas realizadas pela Cooperativa Mista dos Produtores de Leite de Morrinhos (COMPLEM) e de produtos agrícolas cultivados pela Cooperativa dos Agricultores Familiares do Assentamento Tijuqueiro (COOPERFAT), havendo o predomínio das culturas irrigadas de soja, feijão, tomate industrial e milho em áreas que, em passado recente, caracterizavam-se pelo predomínio pleno de vegetação do Cerrado.

A substituição da vegetação natural tem provocado, obviamente, a diminuição da biodiversidade e dos recursos hídricos no município. A situação de devastação do Cerrado causa grande preocupação, e apontamentos efetuados por Carlos Klink e Ricardo Machado (2005) demonstraram que existe correlação entre a perda da diversidade e o endemismo, associados à intensificação dos impactos antrópicos desde a segunda metade do século $\mathrm{XX}$, sobretudo, devido à expansão das atividades agrícolas e pecuárias, que causaram a drástica redução da cobertura vegetal original do Cerrado.

O nível de antropização e degradação da riqueza de espécies e endemismos da região foi o critério principal para inclusão do Cerrado como um dos hotspots mundiais para a conservação da biodiversidade global (MYERS et al., 2000; MITTERMEIER et al., 2004). Devese, ainda, considerar que o mesmo é a segunda maior província fitogeográfica do Brasil (RIBEIRO \& WALTER, 1998), abrangendo as nascentes de importantes rios brasileiros das três maiores bacias hidrográficas da América do Sul: Tocantins-Araguaia, Paraná-Prata e São Francisco (FELFILI \& SILVA JUNIOR, 2005).

O impacto na diminuição da cobertura vegetal e a degradação de recursos hídricos nas fronteiras agrícolas brasileiras são alvos de discussões na sociedade, que geralmente culminam com consequentes efeitos negativos da apropriação do espaço físico - antes ocupado por recursos nativos - e da intensificação do uso do solo, caracterizados pela emissão de poluentes na atmosfera, assoreamento dos rios, aparecimento de erosões, extinção de algumas espécies da fauna e da flora e destruição de ecossistemas frágeis (ROCHA, 2011).

A ocupação da agropecuária iniciou-se de forma intensiva no sul e no sudeste do Brasil. Entretanto, com o esgotamento de terras disponíveis nessas regiões, o direcionamento da produção para áreas de Cerrado no centro-oeste brasileiro tornou-se estratégico pela sua posição geográfica e por suas características físico-ambientais, que propiciavam a expansão da produção agropecuária nos padrões da agricultura moderna, baseada no padrão tecnológico da "Revolução Verde", que incorporou a mecanização, o melhoramento genético de sementes e a aplicação de agrotóxicos e fertilizantes químicos (PIRES, 2000; SILVA, 2000; OLIVEIRA \& DUARTE, 2004; BRANDÃO et al., 2006; DELLA GIUSTINA \& FRANCO, 2014).

A cidade de Morrinhos se projetou em um cenário dinâmico do agronegócio no território goiano, destacando-se no segmento nacional e internacional da agricultura (SANTOS, 2015). Considerando que o produtor rural nesse município vivencia, experimenta e está exposto às transformações do processo de desenvolvimento capitalista e agrário, chegamos ao seguinte questionamento: qual a percepção que os produtores rurais do Assentamento Tijuqueiro (AT), no município de Morrinhos, têm sobre a expansão da produção agropecuária e, consequentemente, sobre a diminuição da cobertura vegetal em áreas de Cerrado no sul do estado de Goiás? Sobre essa indagação, os objetivos deste trabalho foram identificar o perfil do produtor rural morador do AT em Morrinhos, Goiás, e caracterizar as suas concepções sobre o que o Cerrado "era" e as transformações ocorridas de flora e fauna até os dias atuais no município. 


\section{MATERIAL E MÉTODOS}

A presente pesquisa foi empreendida a partir da delimitação da amostra não probabilística intencional (RICHARDSON, 2008). A escolha/definição dos sujeitos participantes do estudo obedeceu aos seguintes critérios/parâmetros:

- ser um produtor rural proprietário de terras e/ou residente no AT, no município de Morrinhos;

- ter idade igual ou superior a 40 anos.

Esclarecemos que o estabelecimento de tais critérios se deveu à necessidade de selecionar sujeito(s) com vivência suficiente para ter podido observar as modificações que vêm ocorrendo no Cerrado há pelo menos 20 anos.

As primeiras informações sobre os possíveis participantes da pesquisa foram obtidas na Empresa de Assistência Técnica e Extensão Rural do Estado de Goiás (EMATER/GO), que apontou a presidência do AT como fonte inicial de informações (dados) para que pudéssemos empreender a pesquisa. Presidência, aliás, que prontamente contribuiu para o nosso propósito primeiro, na medida em que especificou os sujeitos que se encaixavam no perfil por nós definido.

A presidência do AT realizou os primeiros contatos, apresentou os nossos propósitos, agendou as primeiras entrevistas e nos apresentou, pessoalmente, aos participantes do estudo. Tal mediação foi de extrema im- portância para a efetiva realização da pesquisa, pois a apresentação formalizada pela presidência do assentamento junto aos assentados/proprietários estabeleceu uma relação de transparência e de confiança entre esses produtores rurais e os pesquisadores, expressa pela intensidade das informações fornecidas (colhidas).

A maior parte das entrevistas foi realizada nas residências dos sujeitos participantes do estudo. Seguindo as especificações de Roberto Richardson (2008), as coletas de dados foram efetuadas por meio de entrevistas não diretivas, que permitiram aos entrevistados expressar as suas opiniões e informações da maneira que melhor Ihes conviesse; e o entrevistador, por sua vez, desempenhou apenas funções de orientação e estimulação.

Para empreender a análise quantitativa, coletamos informações pessoais dos entrevistados, como ano de nascimento, tempo de residência no AT, que atividades agropecuárias desempenham e demais informações que pudessem ser manifestamente importantes para a execução da pesquisa.

Durante os encontros - realização das entrevistas fizemos uso de gravador de voz e de máquina fotográfica, de acordo com prévia autorização do informante, expressa por meio de assinatura do termo de consentimento livre e esclarecido (TCLE). As informações obtidas foram analisadas quantitativamente, mediante a consideração de frequência absoluta e relativa, produzidas no programa Microsoft Office Excel ${ }^{\circledR} 2013$.

\section{RESULTADOS E DISCUSSÃO}

\section{O Assentamento Tijuqueiro}

Atualmente existem três assentamentos rurais no município de Morrinhos: Assentamento Tijuqueiro I (ATI), Assentamento Tijuqueiro II (ATII) e Assentamento São Domingos dos Olhos D'Água (ASD). As áreas de instalação dos dois primeiros assentamentos eram de propriedade do Governo Federal, mais especificamente, do Ministério da Agricultura (1974-1978). A primeira ocupação das referidas áreas ocorreu em 1986, dando origem ao atual ATI, e constitui, de fato, a primeira etapa de formação do AT, com 20 famílias. Propriedade do Governo Federal, a área ocupada somente poderia ser retomada por meio da ação da Polícia Federal, o que não aconteceu à época.
Mais tarde, o Governo Federal, por meio do Ministério da Agricultura, firmou contrato de cessão de parte da área com o Governo do Estado de Goiás, por um período de dez anos, mais especificamente, à Empresa Goiana de Pesquisa Agropecuária (EMGOPA). A empresa desenvolvia atividades de seleção de sementes e possuía diversos pivôs centrais na produção de arroz, soja e milho. Entretanto, a EMGOPA acabou por encerrar suas atividades em 1998, sendo absorvida pela Empresa de Assistência Técnica e Extensão Rural de Goiás (EMATER/GO).

Vários funcionários, contratados desde a época das pesquisas iniciais empreendidas pela EMGOPA na re- 
gião, foram demitidos de seus cargos, sem observância e respeito pleno aos direitos trabalhistas. Alguns trabaIhadores buscaram a garantia dos seus direitos na justiça. Outro pequeno grupo, formado por apenas cinco ex-funcionários da EMGOPA, completamente insatisfeitos com a situação em que se encontravam, reuniuse, somou forças e decidiu "invadir" a área:

\begin{abstract}
Aí foi ondi mandaram todo mundo embora e não queriam acertar e foi onde eu e minha mãe entrô no consenso de reuni o pessoal. [...] já que eles num qué acertar então vamu pegá a terra. Já abriu falência a empresa não dá conta de tocá, nóis fica com a terra. (J., 38 anos)
\end{abstract}

Para que possamos entender com maior facilidade por que trabalhadores decidem fazer parte de ocupações de terra, precisamos considerar que todos estão em busca de assegurar os seus direitos constitucionais e, nesse caso, também trabalhistas, na perspectiva de um futuro melhor, que pode concretizar-se a partir da deflagração de um processo de ocupação da terra (OLIVEIRA, 2007).

A ocupação durou cerca de oito meses, período no qual várias pessoas permaneceram na área da EMGO$\mathrm{PA}$, levantaram acampamento, alojaram-se em tendas e barracas, pressionando o poder público a encaminhar uma solução para os seus problemas. Em meio ao processo de ocupação, o período de cessão das terras ao Governo do Estado de Goiás havia chegado a termo e a área retornou às mãos do Ministério da Agricultura, sendo em seguida transferida ao Instituto Nacional de Colonização e Reforma Agrária (INCRA) - autarquia subordinada ao atual Ministério do Desenvolvimento Agrário - , que realizou o processo de reforma agrária, dando vida ao AT e estendendo o benefício da propriedade da terra (lote) a outros trabalhadores que não somente os ex-funcionários da EMGOPA.

Eu já tinha uns tantos anos eu já nasci aqui dento $e$ o INCRA falou, não, cê tem direito a uma chácara tamém, nóis era em 6 pessoas que tinha direito de pegá o chão. (J. G., 55 anos)

\section{Caracterização dos entrevistados}

No processo de desenvolvimento da pesquisa, realizamos entrevistas com dez famílias, sendo que quatro entrevistas contaram com a participação do homem e da mulher (casal) proprietários do lote. Destacamos aqui o papel desempenhado pela mu-
O início da ocupação aconteceu em 1998, mas a liberação legal das terras para os futuros moradores transitou pela burocracia administrativa do aparelho do Estado por dois anos e, finalmente, em 2000, os novos proprietários iniciaram as construções de suas casas de alvenaria na área e pagaram para que as terras fossem dividas por igual. A divisão da área beneficiou 15 famílias, que receberam lotes de terras com áreas de 3,5 alqueires e outros de 3,75 alqueires. $O$ aumento na metragem se deveu à ausência de água (rios, ribeirões, lagos, lagoas etc.) em alguns lotes, ou seja, uma pequena compensação em relação àqueles que contavam com tal recurso natural à sua disposição. Essa segunda etapa deu origem ao ATII.

O terceiro assentamento, denominado São Domingos dos Olhos d'Água, está localizado na zona rural de Morrinhos, ocupa a sua porção sudoeste e faz fronteira com o município de Goiatuba. O ASD remete as suas origens à montagem e fixação de um acampamento, que contou com a participação de 85 famílias de trabalhadores rurais no processo de ocupação da antiga Fazenda São Domingos dos Olhos D’Água. Esses trabalhadores empreenderam luta pela posse da terra por sete longos anos, e finalmente a conquistaram em reforma agrária pelo Decreto da Presidência da República do Brasil, publicado aos nove dias do mês de outubro de 1997, legalizando a propriedade dos 85 lotes constituintes do assentamento (SILVA \& SANTOS, 2015).

Esclarecemos que a nossa preocupação em apontar a existência do ASD é relevante pois, além de estar contido em território morrinhense, é um dos maiores assentamentos da região. Porém, não compõe o nosso objeto de estudo; as nossas investigações foram concentradas no AT. Aliás, os contatos, as conversas informais e as entrevistas formais em si apontam a edificação de relações orientadas por conceitos de organização, participação e cooperação entre os assentados, que se expressam por meio da associação dos proprietários (moradores) do AT.

Iher no AT, pois, além de suas responsabilidades domésticas (cuidados com os filhos, com a casa) e com as atividades de produção no campo, ela também se encarrega da comunicação, articulação e liderança no interior da família. 
O trabalho da mulher no assentamento não se restringe aos afazeres do lar. Tal percepção se evidencia nas relações entre marido e mulher, pois sempre que as conversas eram iniciadas, o homem da casa se dirigia à esposa expressando o seu respeito, especialmente quando o assunto se concentrava na organização e no direcionamento das atividades laborais da família. Ao abordar as questões do Cerrado, por exemplo, a mulher deixava o espaço para que o companheiro efetuasse os seus apontamentos e concepções, visto que entendia ser o homem - por seu maior contato e trato direto com a terra - o maior conhecedor do ambiente natural da região.

No desenvolvimento das entrevistas com as outras seis famílias, observamos em algumas ocasiões a presença de um parente e/ou pessoa mais "chegada" (íntima da família), mas em momento algum houve qualquer interferência no desenrolar da conversa. Enfim, entrevistamos 12 moradores do AT, sendo 4 mulheres (34\%) e 8 homens (66\%). A idade variou bastante, entre 38 e 68 anos para as mulheres e entre 39 e 74 anos para os homens - 33,3\% dos sujeitos participantes do sexo masculino possuem idades que variam entre $51 \mathrm{e}$ 70 anos (Tabela 1).

Do número total de entrevistados, a metade (50\%) é natural de Morrinhos. Dentre os sujeitos envolvidos diretamente na pesquisa, $41 \%$ nasceram em cidades goianas como Buriti Alegre, Uruanã, Fazenda do Nor-

\section{As modificações no Cerrado}

A primeira grande evidência observada se remete à homogeneidade na linguagem expressa pelos assentados entrevistados, sendo marcante a forma como expõem os seus conhecimentos sobre as plantas e os animais te e Aloândia. Apenas 1 assentado (0,9\% dos entrevistados) não é natural do estado de Goiás, e nasceu no município de Picos, no estado do Piauí. De acordo com as informações prestadas pelos entrevistados, em média eles vivem há 22,3 anos no AT. Salientamos que somente 3 assentados residem há menos de 20 anos na região, sendo moradores da segunda etapa do AT, que foi mais recente (1998 - ATII).

A principal atividade produtiva do AT está concentrada na pecuária, mais especificamente na produção leiteira, sendo vinculada à Cooperativa dos Agricultores Familiares do Assentamento Tijuqueiro (COOPERFAT) e à empresa Goiasminas Indústria de Laticínios Ltda. (ITALAC ${ }^{\circledR}$ ). Os assentados entrevistados produzem e repassam à ITALAC $^{\circledR}$, diariamente, entre 150 e $300 \mathrm{li}$ tros de leite. Alguns, entretanto, chegam a produzir 500 litros/dia. Os trabalhadores rurais do AT também dedicam parte de suas atividades à agricultura, produzindo culturas como milho para silagem, mandioca, abóbora e verduras.

Em pesquisa realizada na bacia do Tijuqueiro, publicada em 2011, Aderbal Rocha apontou que a produção de mais de 70 milhões de litros de leite por ano (naquele momento) colocou o município de Morrinhos na posição de segundo maior produtor leiteiro do estado. O pesquisador destaca, ainda, a importância do rebanho bovino destinado ao corte e à seleção de reprodutores para a economia do município.

característicos do Cerrado; há significativa concordância das informações fornecidas que o Cerrado na região foi modificado pela diminuição da biodiversidade local. $\mathrm{O}$ argumento principal, como resposta às modificações

Tabela 1 - Faixa etária e gênero dos sujeitos participantes da pesquisa.

\begin{tabular}{|c|c|c|c|c|}
\hline Faixa etária & Feminino & Masculino & $\begin{array}{c}\text { Frequência } \\
\text { absoluta }\end{array}$ & $\begin{array}{c}\text { Frequência } \\
\text { relativa (\%) }\end{array}$ \\
\hline $30-40$ & 1 & 1 & 2 & 16,6 \\
\hline $41-50$ & 0 & 1 & 1 & 8,4 \\
\hline $51-60$ & 2 & 2 & 4 & 33,3 \\
\hline $71-70$ & 1 & 3 & 4 & 33,3 \\
\hline Total & 0 & 1 & 1 & 8,4 \\
\hline
\end{tabular}


ocorridas, é de que o desmatamento, a devastação do Cerrado, vem ocorrendo há mais de 30 anos, ou seja, quando chegaram à região, a destruição da vegetação natural era realizada em marcha plena.

As experiências e atividades produtivas agrícolas empreendidas pela EMGOPA e, mesmo anteriormente, pelo Ministério da Agricultura, já tinham devastado o que havia de Cerrado na área, sobretudo pela utilização de pivôs centrais. Outros apontam, ainda, que a construção de uma rodovia estadual também contribuiu para a destruição da vegetação natural na região. Estima-se que o desmatamento para a realização das obras da rodovia tenha atingido entre dois e três hectares de mata nativa.

Outras ocorrências se impõem ao Cerrado de um modo geral, como as grandes transformações provocas por queimadas, seca e intervenções antrópicas como pastagem, agricultura, remoção de árvores para carvão etc. (REZENDE et al., 2005). As nossas preocupações concentram-se nas nefastas consequências produzidas por tais ocorrências, pois impactam diretamente o dinamismo do Cerrado. Ao que a experiência indica, parece não haver possibilidades concretas para a sustentabilidade dessas áreas manejadas, que fragilizam intensivamente o bioma Cerrado e reduzem significativamente a sua biodiversidade.

Diante das informações coletadas, podemos inferir que a maior parte das áreas desmatadas, talvez a sua totalidade, abrigava espécies de plantas e animais não conhecidas pela maioria da população local e, portanto, não foram identificadas (catalogadas) cientificamente. Nesse contexto, são inegáveis as consequências danosas que o desmatamento causa: dano biológico irreversível, irreparável, na medida em que possíveis espécies promissoras para o tratamento e/ou cura de doenças que acometem o homem poderiam ter sido identificadas e aplicadas para tal fim, por exemplo.

Alguns entrevistados, moradores de uma região de baixada do AT, relataram que o acesso a algumas áreas remanescentes de matas nativas era bastante difícil no passado. Argumentaram ainda que, desde a ocupação da área do AT até os dias atuais, a devastação foi mínima se comparada à situação em que a região se encontrava à época que era explorada pela EMGOPA; o estrago já havia sido feito.
Embora haja um discurso similar entre os sujeitos participantes da pesquisa sobre o desmatamento anterior à ocupação, todos demonstraram grande preocupação com a necessidade de preservação do Cerrado. Constatamos em momentos diversos a preocupação dos assentados com a importância de se destinar uma área de cada propriedade à reserva florestal; o que expressa, por si só, a consciência ambiental desses trabalhadores rurais.

Portanto, torna-se evidente a existência de uma concepção que considera a correlação entre a necessidade e a importância da existência de reserva em cada propriedade e transforma em tarefa cotidiana os cuidados com os remanescentes florestais. De acordo com David Pimentel et al. (1992), os fragmentos florestais remanescentes em áreas alteradas podem servir como áreas tampões diante da variação microclimática (visto que ajudam a reduzir a perda de água e a ocorrência de erosões) e aumentar a biodiversidade nas áreas de plantações e/ou pastagens.

O entrevistado X. (68 anos) relata que há 40 anos toda a área correspondente ao AT era mata e, à medida que a produção agrícola se expandiu, provocou consequentemente o aumento do desmatamento. Prossegue o nosso entrevistado $X$. com os seus apontamentos, afirmando que na época da formação do ATII (1998-2000), a área ocupada era parte constituinte da reserva do Ministério da Agricultura.

Os espaços no interior dos assentamentos que possuíam áreas verdes, na realidade, constituíam as áreas de cultivo agrícola desenvolvidas pelos assentados, com vistas, inclusive, a garantir sombra para o gado leiteiro e, também, como reserva legal. Após a ocupação, formação e legalização dos assentamentos ATI e ATII, da área total de 70 alqueires, restaram apenas 9 ou 10 alqueires de vegetação nativa do Cerrado.

Aproximadamente $86 \%$ da área original foi transformada em pastagens, ou destinada à produção agrícola, acirrando a discussão sobre a destruição do Cerrado. Vejamos os seguintes fragmentos:

Diminuiu bastante, e vem diminuindo, a flora vem diminuindo cada dia, né? Cada dia o homem é o animal mais terrível que tem, né? Vai diminuindo mesmo. $\mathrm{O}$ que Deus gasta 30 anos o homem dirruba em 2, 3 dias. (A. L., 39 anos) 
Obrigação de cada posseiro é plantá 100 árvore todo ano e aí 15 a 20 ano teria uma reserva, não a que tinha antes, 12 alqueires. Uns 10 a 15 ano. (J. G., 55 anos)

Outro problema apontado se remete ao pisoteio do gado em áreas com nascentes d'água, o que provoca o soterramento e desaparecimento das mesmas, reduzindo a disponibilidade de recurso tão importante (fundamental) nas terras do assentamento. A preocupação com a preservação do meio ambiente é permanente e reflete tanto a sabedoria da relação causa e efeito na natureza, como promove o debate entre os assentados, pois mantém o sinal de alerta acesso em relação à destruição dos recursos naturais e, portanto, do meio ambiente.

A assistência tecnológica no campo é entendida por muitos trabalhadores rurais como um avanço da agropecuária na região. Exemplo do emprego de recursos tecnológicos nas atividades laborais do assentamento é verificado na produção leiteira: há 4 anos eram produzidos 130 litros de leite por dia; atualmente, com a utilização da ordenha mecânica, a produção por dia gira em torno de 350 a 400 litros, um aumento médio de $300 \%$ na produção diária.

Contudo, outra parcela de assentados responsabiliza o desenvolvimento tecnológico e o emprego de máquinas no processo produtivo como um dos grandes responsáveis pela expansão indiscriminada do desmatamento. Em passado recente, o que demandava exclusivamente a força de trabalho do homem, agora se realiza facilmente com a utilização de tratores de última geração no trabalho rural.

Diante da submissão do Cerrado à ação da motosserra, do fogo, da destoca com lâmina e da gradagem, a sustentabilidade das formações vegetais desse bioma precisa ser assegurada, é preciso promover o estabelecimento da regeneração natural de espécies após a ocorrência de tantos distúrbios.

Alba Rezende et al. (2005) afirmam que esse bioma vem conseguindo recuperar a sua riqueza florística, o que pode caracterizá-lo como um sistema resiliente que, ao ser modificado por distúrbios externos, retorna à sua condição de equilíbrio original de forma gradativa. Manoel Guariguata e Juan Dupuy (1979) argumentam que a compactação do solo decorrente da utilização frequente de máquinas e/ou sistemas me- canizados dificulta o desenvolvimento da flora e causa atraso no processo regenerativo.

As nossas inquietações a respeito da regeneração do Cerrado suscitam o seguinte questionamento: mesmo que o bioma Cerrado apresente resiliência em sua recuperação natural, será mesmo que os produtores rurais respeitarão a relação espaço-tempo para que tal processo regenerativo se concretize?

Outro aspecto abordado pelos assentados e encarado como positivo diz respeito à adubação artificial com a utilização de fertilizantes químicos, pois se tornou possível cultivar determinados tipos de grãos nunca praticados na produção agrícola do Cerrado, conforme argumenta D. G. (63 anos):

\footnotetext{
E daí foi isso, chegou fazendo as lavoura e umas pessoas até chamam que o arroz passou a ser o desbravador do cerrado. É isso, a transformação veio o desmatamento, vem a tecnologia, vem plantio, vem muito produto, adubo, lembro da primeira lavoura de adubo que eu vi de arroz, começou a plantá arroz no cerrado mesmo, terra vermelha não se plantava arroz, ai nos plantamo, primeiro arroz que eu vi plantá cuidá e colhe o arroz, mas muito fraco, dava pouco, o rendimento pequeno. Daí uns tempos um parente meu plantou, mas eu não sabia, passei no meio daquela lavoura depois de colhido e assustei com aquela lavoura, o tanto que ela tinha sido boa um arroz, bom demais e perguntei alguém o que o Manoel fez com aquele arroz que ele ficou bom demais, me falaram que é porque ele tinha usado adubo, mas eu não sabia o que era adubo, e perguntei o que era isso porque não conhecia, ai me falaram que é um produto que tinha colocado no pé do arroz que ele cresce demais e desenvolve demais. Ai foi crescendo adubo para fazer correção de solo, e tudo isso foi acontecendo e o desbravamento do cerrado se deu ai, mas foi muito maquinário, muito maquinário, ai desmatou mesmo [...]. (D. G., 63 anos)
}

Esse relato, em si, expressa o papel desempenhado pela modernização e expansão da agricultura no processo de destruição do Cerrado; não apenas expressa a ocorrência do desmatamento, mas também o abandono e a consequente desintegração da produção agrícola tradicional, reforçada pelo crescimento do êxodo rural. De acordo com os sujeitos participantes desta pesquisa, muitos trabalhadores rurais perderam seus empregos em virtude da introdução das máquinas no processo produtivo agropecuário. 
As grandes fazendas possuíam os denominados agregados ou meeiros, encarregados do trabalho geral nessas terras, que recebiam uma parte da terra para trabalhar e a outra parte para produzir para os grandes fazendeiros. Quando as máquinas chegaram ao campo, os fazendeiros simplesmente dispensaram essa mão de obra. Os agregados e meeiros foram obrigados a deixar as terras que tinham cultivado e perderam tudo que produziram com o seu trabalho. A maior incidência de êxodo rural no município de Morrinhos foi verificada na década de 1960, momento em que muitos agricultores deixaram o campo em busca de novas oportunidades na cidade.

Na esteira das transformações ocorridas em Morrinhos, Rildo Costa e Flávia Santos (2010) apontam as mudanças implementadas no processo produtivo da soja no estado de Goiás, que passou a ser realizado, sobretudo, em médias e grandes propriedades rurais com a intensa utilização de máquinas e insumos químicos em substituição à mão de obra do trabaIhador rural. Eliminação de mão de obra que incidiu na desintegração da agricultura familiar, na medida em que os pequenos produtores, sem condições de subsistir, buscaram a vida na cidade. Um verdadeiro holocausto para a sustentabilidade. Atualmente observamos um movimento na direção contrária: a busca pelo desenvolvimento sustentável, ainda que tímida em nosso país. A manutenção da agricultura familiar tem ganhado espaço, como perspectiva de um continuum para a preservação dos recursos naturais.

O processo de mapeamento dos solos com o auxílio do sensoriamento remoto para o monitoramento e manejo das propriedades rurais também contribui substancialmente para a devastação do Cerrado e tem sido apontado como responsável pela fragmentação da vegetação nativa, devido às grandes extensões utilizadas nas atividades produtivas agropecuárias na atualidade, à insuficiência e/ou ausência de planejamento preventivo de impactos negativos que o acompanha; bem como aos efeitos diretos e indiretos gerados por tal processo, como a poluição das águas, da atmosfera, a compactação dos solos e a erosão, dentre outros (FARIA \& CASTRO, 2007).

Outro grande problema constatado no desenvolvimento da pesquisa, para além das áreas já desmatadas, é o crescimento do corte de madeira nativa para a construção ci- vil, para a edificação de cercas (mourão) e para a queima (lenha/carvão). A solução se encaminhou - por boa parte dos produtores rurais - para a plantação de eucalipto, tendo em vista evitar a retirada de madeira da mata.

Observamos uma interessante distinção das áreas de Cerrado na concepção dos assentados: a primeira diz respeito aos campos limpos e de baixa fertilidade, que ocorrem em áreas acidentadas como vales e baixadas; a segunda concepção se remete às terras ricas e férteis, denominadas de "mato", ou de "cultura", onde são encontradas as madeiras de lei - jatobá e aroeira. "Cerrado é diferente de mato. Cerrado é um mato baixo de madeira ruim. $\mathrm{E}$ o mato é de madeira boa" (J. B., 54 anos).

Ocupamo-nos, ainda, em listar todas as espécies vegetais e animais citadas pelos sujeitos participantes da pesquisa. As espécies estão dispostas por seus nomes populares nas Tabelas 2 e 3, contudo, não houve observação in loco dos exemplares, pois as citações foram baseadas nas histórias de vida, nas lembranças pessoais dos entrevistados de um passado em que o Cerrado era formado por diversificados componentes da flora e da fauna.

Os nomes científicos listados foram pesquisados na literatura básica de plantas e animais nativos do Cerrado brasileiro. Somente duas espécies vegetais, o sorgo e o cipó-quadrado, não apresentam nome científico, visto que o único sorgo listado na literatura é cultivado, porém, na entrevista, a planta foi citada como a árvore de sorgo; e o cipó-quadrado não foi encontrado na literatura. Em excursão pela mata, todos os entrevistados demonstraram amplo conhecimento sobre as plantas que existiam em abundância na região.

As plantas mais citadas como extintas na região de Morrinhos foram: jatobá, angico, aroeira e araticum. Algumas espécies como angico e pau-d'óleo foram apontadas como plantas medicinais, outrora utilizadas como remédio. As plantas frutíferas vinham às lembranças dos entrevistados como algo único e especial e faziam reluzir os olhos ao mesmo tempo em que expressavam no olhar o prazer de coIher uma fruta no pé, como a gabiroba, a mangaba e o araticum. 
Os assentados, além de apontarem a ocorrência de uma grande diversidade de animais no Cerrado, ainda especificaram alguns traços fundamentais do comportamento de parte deles, como veado (catingueiro), guariba, tamanduá-mirim (meleta), beijaflor, gavião-carcará, quati, paca, cotia, onça-vermeIha, onça-preta, caititu e lobo-guará, animais que não são mais vistos na região. Outros, como inhambu, tucano, macaco, capivara, tamanduá-bandeira e jacaré, que eram sempre vistos, hoje são raros, praticamente desapareceram.

O tamanduá-bandeira, o macaco-prego e o lobo-guará estão presentes nas listas das espécies da fauna brasileira ameaçadas de extinção (BRASIL, 2014). A vulnerabilidade desses animais na natureza depende do grau de desmatamento do Cerrado nos próximos anos. As espécies hoje presentes no Cerrado e a categoria vulnerável para elas apresentada, demostram que, se o avanço da agropecuária e o desmatamento persistirem nos próximos anos, certamente esses animais serão levados à extinção.

Das poucas espécies de aves avistadas no desenvolvimento da pesquisa, apontamos as araras como representativas remanescentes de um grupo que luta insistentemente por sua sobrevivência no Cerrado de Morrinhos, devastado pela intensiva produção agropecuária.

Lamentavelmente, os apontamentos, os relatos, os argumentos expressos pelos sujeitos participantes

Tabela 2 - Espécies vegetais citadas pelos entrevistados.

\begin{tabular}{|c|c|c|}
\hline & Nome comum & Nome científico \\
\hline 1 & Jatobá & Hymenaea sp. \\
\hline 2 & Angico & Piptadenia sp. \\
\hline 3 & Aroeira & Schinus sp. \\
\hline 4 & Pequi & Caryocar sp. \\
\hline 5 & Carvoeiro & Sclerolobium sp. \\
\hline 6 & Capitão & Terminalia sp. \\
\hline 7 & Sucupira & Bowdichia sp. \\
\hline 8 & Amarelinho & Plathymenia sp. \\
\hline 9 & Sorgo & Espécie desconhecida \\
\hline 10 & Araticum & Annona sp. \\
\hline 11 & Paineira & $*$ \\
\hline 12 & Cipó-quadrado & $*$ \\
\hline 14 & Guapeba & Chrysophyllum sp. \\
\hline 15 & Jacarandá & Jacaranda sp. \\
\hline 16 & Gabiroba & Campomanesia sp. \\
\hline 17 & Mangaba & Hancornia sp. \\
\hline 18 & Baru & Dypterix sp. \\
\hline 19 & Pau-d'óleo & Copaifera sp. \\
\hline 20 & Maria-preta & Solanum sp. \\
\hline 21 & Cafezinho & Cordia sp. \\
\hline *omo diversificadas/desconhecidas as espécies dessas plantas no Cerrado não foi especificado o nome científico. \\
\hline
\end{tabular}


do estudo refletem os prazeres vividos de um Cerrado em tempo ido. De um Cerrado em que era possível e perfeitamente natural apanhar um fruto no interior da "mata", amplamente povoada por uma diversidade animal riquíssima, praticamente dizimada pela ação destrutiva das atividades produtivas do capital. Entretanto, são tais lembranças que persistem e insistem em manter viva a preocupação com a preservação dos remanescentes florestais na região de Morrinhos, na perspectiva de conservar o que restou do patrimônio natural denominado Cerrado do Brasil.

Tabela 3 - Espécies animais citadas pelos entrevistados.

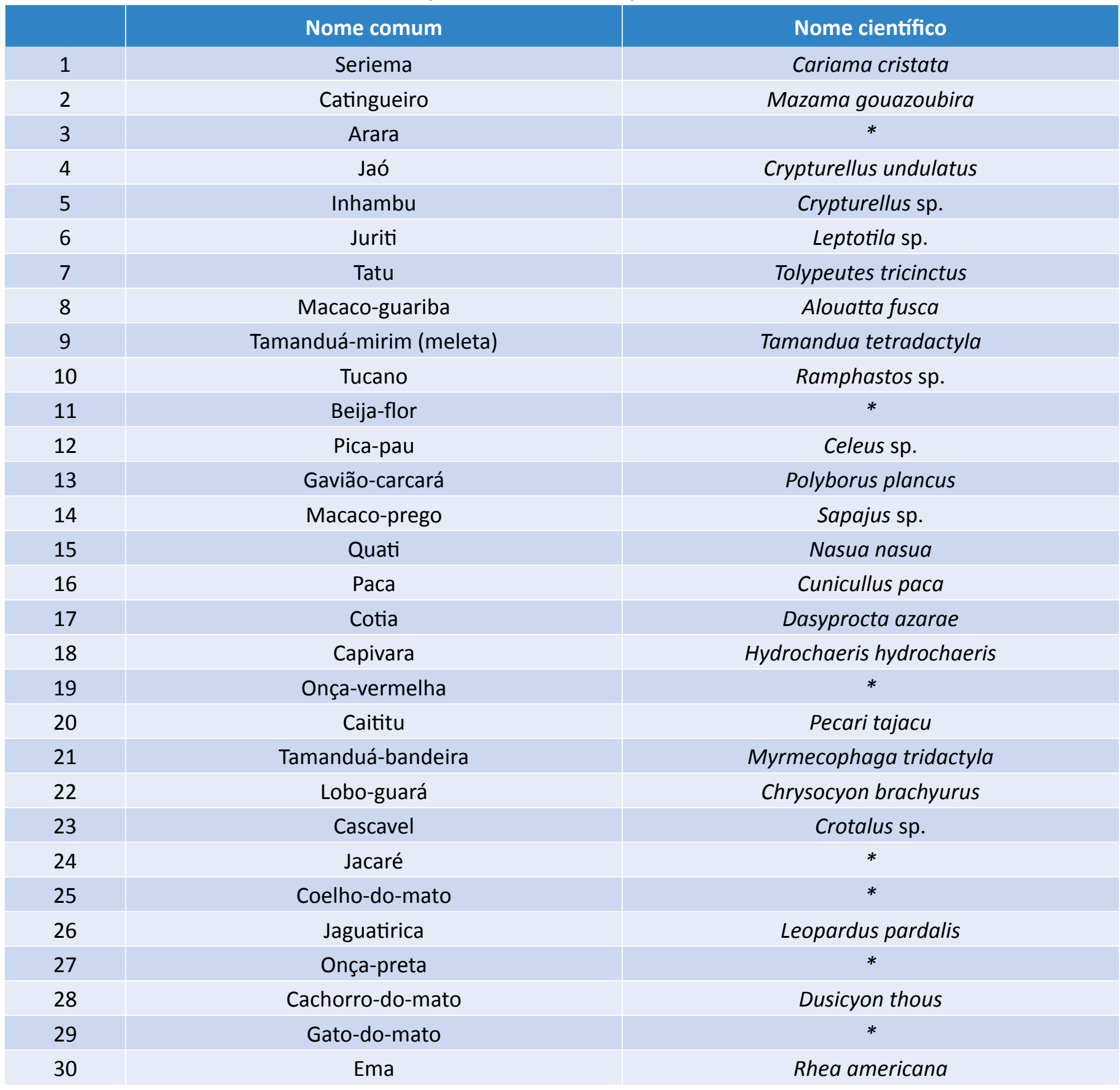

*como são diversificadas as espécies dessas plantas no Cerrado não foi especificado o nome científico. 


\section{CONCLUSÕES}

O perfil dos entrevistados nesta pesquisa nos faz crer na importância do papel da mulher moradora do AT; por mais que haja uma separação espacial de trabalho e de gênero no conhecimento das áreas em que vivem esses produtores, na estrutura social as mulheres demonstraram dominância na organização de suas propriedades rurais.

No histórico narrado da construção do AT no município de Morrinhos, observamos uma unanimidade dos relatos que apontam uma devastação já existente na região antes da tomada de terra pelos assentados. Conclui-se, então, que as experiências e atividades produtivas agropecuárias realizadas no município de Morrinhos há muito têm contribuído para dizimar a vegetação natural do Cerrado desde a década de 1960 com a ampliação da utilização de pivôs centrais na produção agrícola, mais especificamente. Assim como a ocorrência de queimadas, tanto os períodos estendidos de seca (decorrentes de fenômenos climáticos) quanto as intervenções antrópicas, que aumentam as áreas de pastagem e de produção agrícola mediante a remoção de árvores, também têm contribuído substancialmente para a devastação do Cerrado.
Na leitura da história de vida dos assentados, a existência ou ausência de uma planta ou animal do Cerrado nos permite afirmar seguramente que inúmeras espécies deixaram de ser conhecidas em decorrência do processo de desmatamento e destruição da vegetação natural do Cerrado. Consequências extremamente maléficas para o meio ambiente e para a humanidade, pois o atendimento permanente às demandas impostas pela economia capitalista tem causado danos irreversíveis, irreparáveis, irremediáveis ao meio natural.

Inferimos ainda que os trabalhadores rurais do AT expressam a sua mais objetiva consciência da atual condição do Cerrado. Suas afirmações e argumentos convergem e expressam a grande preocupação com a urgente necessidade de se preservar o pouco que restou da vegetação natural original na região de Morrinhos. Os assentados do Tijuqueiro reiteram que é preciso empreender ações imediatas, como a destinação de áreas em suas propriedades à criação de reservas florestais - se não para reverter a deplorável situação do Cerrado, pelo menos para que essas ações sirvam para evitar a expansão da destruição.

\section{REFERÊNCIAS}

BRANDÃO, A. S. P.; REZENDE, G. C. de; MARQUES, R. W. da C. Crescimento agrícola no período 1999/2004: a explosão da soja e da pecuária bovina e seu impacto sobre o meio ambiente. Economia Aplicada, São Paulo, v. 10, n. 2, p. 249266, abr./jun. 2006. Disponível em: <http://www.scielo.br/pdf/ecoa/v10n2/a06v10n2.pdf>. Acesso em: 26 jun. 2017.

BRASIL. Portaria MMA n. 443, de 17 de dezembro de 2014. 2014. Disponível em: <http://www.icmbio.gov.br/cepsul/ images/stories/legislacao/Portaria/2014/p_mma_443_2014_lista_espécies_ameaçadas_extinção.pdf>. Acesso em: 10 nov. 2015.

COSTA, R. A.; SANTOS, F. de O. Expansão agrícola e vulnerabilidade natural do meio físico no sul goiano. Geografia em Atos, Presidente Prudente, v. 2, n. 10, jul./dez. 2010. Disponível em: <http://revista.fct.unesp.br/index.php/ geografiaematos/article/view/270>. Acesso em: 23 set. 2015.

DELLA GIUSTINA, C. C.; FRANCO, J. L. de A. O Uso Insustentável dos Recursos Naturais no Estado de Goiás: Efeitos da agricultura na conservação do bioma Cerrado. Fronteiras: Journal of Social, Technological and Environmental Science, Anápolis, v. 3, n. 1, p. 55-65, jan./jul. 2014. Disponível em: <http://revistas.unievangelica.com.br/index.php/fronteiras/ article/view/764/771>. Acesso em: 27 jun. 2017.

FARIA, K. M. S.; CASTRO, S. S. Uso da terra e sua relação com os remanescentes de cerrado na alta bacia do rio Araguaia (GO, MT e MS). Geografia, Rio Claro, v. 32, n. 3, p. 657-668, set./dez. 2007. Disponível em: <http://www.labogef.iesa.ufg. br/labogef/arquivos/downloads/Karla_Selma_UsodoSoloesuasRelacoes_12127_00313.pdf>. Acesso em: 20 set. 2015. 
FELFILI, J. M.; SILVA JUNIOR, M. C. da. Diversidade alfa e beta no cerrado sensu strictu, Distrito Federal, Goiás, Minas Gerais e Bahia. In: SCARIOT, A.; SOUSA-SILVA, J. C.; FELFILI, J. M. (Orgs.). Cerrado: Ecologia, biodiversidade e conservação. Brasília: Ministério do Meio Ambiente, 2005. p. 141-154. Disponível em: <http://www.mma.gov.br/estruturas/chm/_ arquivos/17_Cap\%207.pdf>. Acesso em: 29 jun. 2017.

GUARIGUATA, M. R.; DUPUY, J. M. Forest regeneration in abandoned logging in lowland Costa Rica. Biotropica, St. Louis, v. 29 , n. 1 , p. $15-28,1979$.

INSTITUTO BRASILEIRO DE GEOGRAFIA E ESTATÍSTICA (IBGE). Cidades@. Disponível em: <http://www.cidades.ibge. gov.br/xtras/perfil.php?lang=\&codmun=521380\&search=|| infogr\%E1ficos:-informa\%E7\%F5es-completas $>$. Acesso em: 29 mar. 2015.

KLINK, C. A.; MACHADO, R. B. A conservação do Cerrado brasileiro. Megadiversidade, v. 1, n. 1, jul. 2005. Disponível em: <https://www.researchgate.net/publication/228342037_A_conservacao_do_Cerrado_brasileiro>. Acesso em: 26 ago. 2015.

MITTERMEIER, R. A.; ROBLES GIL, P.; HOFFMANN, M.; PILGRIM, J.; BROOKS, T.; MITTERMEIER, C. G.; LAMOREUX, J.; FONSECA, G. A. B. Hotspots revisited: Earth's biologically richest and most endangered terrestrial ecoregions. Cidade do México: CEMEX/Agrupación Sierra Madre, 2004.

MYERS, N.; MITTERMEIER, R. A.; MITTERMEIER, C. G.; FONSECA, G. A. B.; KENT, J. Biodiversity hotspots for conservation priorities. Nature, v. 403, p. 853-858, 2000. Disponível em: <https://www.nature.com/nature/journal/v403/n6772/ pdf/403853a0.pdf>. Acesso em: 28 jun. 2017.

OLIVEIRA, E. de; DUARTE, L. M. G. Gestão da biodiversidade e produção agrícola: o Cerrado goiano. Cadernos de Ciência e Tecnologia, Brasília, v. 21, n. 1, p. 105-142, jan./abr. 2004. Disponível em: <https://biotek.iesa.ufg.br/up/160/o/ GEST_O_DA_BIODIVERSIDADE_E_PRODU_O_AGR_COLA.pdf>. Acesso em: 28 jun. 2017.

OLIVEIRA, M. L. R. de. Retratos de assentamentos: um estudo de caso em assentamentos rurais formados por migrantes na região do entorno do Distrito Federal. 212 f. Tese (Doutorado em Ciências Sociais em Desenvolvimento, Agricultura e Sociedade) - Universidade Federal Rural do Rio de Janeiro, Seropédica, 2007. Disponível em: <http:// www.riopomba.ifsudestemg.edu.br/portal/sites/default/files/arq_paginas/1tese_marcelo_romarco.pdf $>$. Acesso em: 25 ago. 2015.

PIMENTEL, D.; STACHOW, U.; TAKACS, D. A.; BRUBAKER, H. W.; DUMAS, A. R.; MEANEY, J. J.; O'NEIL, J. A. S.; ONSI, D. E.; CORZILIUS, D. B. Conserving biological diversity in agricultural/forestry systems. BioScience, v. 42, n. 5, maio 1992.

PIRES, M. O. Programas agrícolas na ocupação do Cerrado. Sociedade e Cultura, Goiânia, v. 3, n. 1-2, p. 111-131, jan./ dez. 2000. Disponível em: <http://www.redalyc.org/pdf/703/70312129007.pdf>. Acesso em: 28 jun. 2017.

REZENDE, A. V.; SANQUETTA, C. R.; FIGUEIREDO FILHO, A. Efeito do desmatamento no estabelecimento de espécies lenhosas em um cerrado Sensu stricto. Floresta, Curitiba, v. 35, n. 1, 2005. Disponível em: <http://ojs.c3sl.ufpr.br/ojs/ index.php/floresta/article/view/2432>. Acesso em: 23 ago. 2015.

RIBEIRO, J. F.; WALTER, B. M. T. Fitofisionomias do bioma cerrado. In: SANO, S. M.; ALMEIDA, S. P. (Eds.). Cerrado: ambiente e flora. Planaltina: Embrapa Cerrados, 1998. p. 89-166.

RICHARDSON, R. J. Pesquisa social: métodos e técnicas. 3. ed. São Paulo: Atlas, 2008.

ROCHA, A. A. Monitoramento de agrotóxicos em áreas irrigadas por pivô central na microbacia do Tijunqueiro, Município de Morrinhos, Goiás. 145 f. Tese (Doutorado em Ciências) - Universidade de São Paulo, 2011. Disponível em: <http://www.teses.usp.br/teses/disponiveis/64/64135/tde-30092011-095524/en.php>. Acesso em: 29 mar. 2015. 
SANTOS, M. S. dos. O processo de modernização da agropecuária e o agronegócio: a dinâmica territorial na microrregião da Meia Ponte e no município de Morrinhos (GO), 1970-2010. 98 f. Dissertação (Ciências Sociais e Humanidades) - Universidade Estadual de Goiás, Anápolis, 2015. Disponível em: <http://www.cdn.ueg.br/source/ teccer/conteudoN/4829/Dissertao_Marlus_TECCER.pdf>. Acesso em: 29 jun. 2017.

SILVA, A. M.; SANTOS, F. R. Formação educacional e evasão escolar dos alunos da zona rural no município de Morrinhos (GO). In: SEMINÁRIO INTERNACIONAL DE HISTÓRIA DA UEG, 1., Morrinhos, set. 2015. Caderno de Programação e Resumos... 2015. Disponível em: <http://www.cdn.ueg.br/source/simposio_internacional_de_historia_da_ueg_166/ noticias/21658/CadernodeProgramaoSIH2015_final_1.pdf>. Acesso em: 20 dez. 2015.

SILVA, L. L. O papel do estado no processo de ocupação das áreas de cerrado entre as décadas de 60 e 80 . Caminhos de Geografia, v. 1, n. 2, p. 24-36, dez. 2000. 